\title{
Heavy Metal Profile of Shilajit Samples Obtained from Gilgit and Chellas, Pakistan (Short Communication)
}

\author{
Muhammad Rahim, ${ }^{1,2^{*}}$ Imdadullah Mohammadzai, ${ }^{1}$ Waseem $\operatorname{Hassan}^{3}$ and Nazir Ahmad ${ }^{1}$ \\ ${ }^{1}$ Institute of Chemical Sciences, University of Peshawar, Peshawar, K. P., Pakistan \\ ${ }^{2}$ School of Chemical Sciences, Universiti Sains Malaysia, \\ 11800 USM Pulau Pinang, Malaysia \\ ${ }^{3}$ Departamento de Química, Centro de Ciências Naturais e Exatas, Universidade Federal \\ de Santa Maria, Santa Maria, CEP 97105-900, RS, Brazil \\ *Corresponding author:kpk566@gmail.com
}

Published online: 25 August 2016

To cite this article: Rahim, M. et al. (2016). Heavy metal profile of shilajit samples obtained from Gilgit and Chellas, Pakistan. J. Phys. Sci., 27(2), 139-144, DOI: 10.21315/jps2016.27.2.10

To link to this article: http://dx.doi.org/10.21315/jps2016.27.2.10

\begin{abstract}
Shilajit is considered as one of the wonder medicines of Ayurveda. It is an important drug of the ancient Hindu medication and until present day it is being used extensively for a variety of diseases. However, there are a number of reports which have associated metal poisoning with traditional use of herbal medicine including Shilajit. This study aims to determine the prevalence and concentration of heavy metals in Shilajit obtained from natural valleys of Gilgit (sample A) and Chellas (sample B) which are commonly used in Pakistan. Determination of heavy metals was carried out using atomic absorption spectrophotometry. Iron, zinc, chromium, manganese, cobalt and lead were detected in both samples. The percentages of these metals in sample A were $0.19680 \%$, $0.08705 \%, 0.01138 \%, 0.0026 \%, 0.00051 \%$ and $0.00008 \%$, respectively, while sample $B$ contains these metals in the following percentages: $0.03210 \%, 0.00213 \%, 0.00154 \%$, $0.00147 \%, 0.00055 \%$ and $0.00023 \%$. Our data indicated that the metal concentration in both tested samples are within permissible level as prescribed by World Health Organization (WHO) and are not associated with detrimental health effects.
\end{abstract}

Keywords: Shilajit, toxicity and metal concentration, metal profile, herbal medicine, atomic absorption spectrophotometry

\section{INTRODUCTION}

Shilajit is a blackish-brown exudation, from steep rocks of different formations, commonly found in the Himalayas at altitudes around 1000-5000 m, from Arunachal Pradesh in the East to Kashmir in the West. It is also found in 
Afghanistan (Hindukush), Bhutan, China, Nepal, Pakistan, Tibet (Himalayan belt) and the USSR (Ural-Tien-Shan). Shilajit is believed to slow down aging and produce rejuvenation. ${ }^{1}$

Literature suggests that there are six types of Shilajit based on the corresponding six types of metal from which it exudes: gold, silver, copper, iron, tin and lead. Each type has the same taste and potency as the metal to whose essence it owes its origin. Shilajit derived from tin, lead, iron, copper, silver and gold are progressively more efficacious in their nature. ${ }^{2}$ The black form of Shilajit is the most commonly used medicinal form. ${ }^{3}$ The general appearance of Shilajit is that of a compact mass of vegetable organic matter composed of a dark-red gummy matrix interspersed with vegetable fibres, sand and earthy matter. The gummy substance dissolves in water and when washed away leaves an earthy matter, vegetable fibres and a black round button-like masses (1/8 inches in diameter) resembling pea size. ${ }^{4}$

Chemical analysis shows that Shilajit contains gums, albuminoids, traces of resin and fatty acid, a large quantity of benzoic, as well as hippuric acids and their salts. From the medicinal point of view, the chief active substances are benzoic acid and benzoates. ${ }^{5}$ Shilajit has long been regarded as a bitumen (asphalt) or mineral resin, or as a plant fossil exposed by elevation of the Himalayas. Chemical investigations have shown that it contains significant quantities of organic compounds, including bioactive oxygenated dibenzo-alpha-pyrones, tirucallane triterpenes, phenolic lipids and small tannoids. Shilajit, obtained from different sources, has now been standardised on the basis of its major organic constituents. ${ }^{5}$ Shilajit is essentially constituted of fresh and modified remnants of humus $(10 \%-70 \%$ of the water-soluble fraction of Shilajit), admixed with plant and microbial metabolites occurring in the rock rhizosphere of its natural habitat. ${ }^{6}$

Traditionally, Shilajit is used in dermatological, gastrointestinal, haematological, lymphatic, immunology, cancer and infectious diseases. ${ }^{2,7}$ While modern indications suggest that Shilajit can also reduce blood sugar. ${ }^{8}$ But despite its growing use since 1978, a number of cases of heavy metal intoxication associated with ayurvedic herbal medicine products (HMPs) in adults and children have been reported worldwide. ${ }^{9}$ Heavy metal estimation is therefore mandatory to avoid metal intoxication. However, in the literature there is scarcity of data about heavy metals estimation in traditional medicine, i.e., Shilajit in Pakistan. For this purpose, we determined heavy metal content in Shilajit samples obtained from two popular valleys of Pakistan i.e., Gilgit and Chellas. 


\section{RESULTS AND DISCUSSION}

Two samples of Shilajit were studied from Gilgit and Chellas. Sample obtained from Gilgit was coded "A" and that from Chellas coded "B" for identification. Atomic absorption spectrophotometer (700 Perkin Elmer) was used in the experiment. Analytical grade chemicals with purity of $99.9 \%$ (Merck Darmstadt, Germany) were used during experimental analysis. Standard solutions of each metal were prepared by dilution of $1000 \mu \mathrm{g} \mathrm{m}^{-1}$ certified standard solutions (Fluka Kamica Busch, Switzerland) of the respective metals. The known amount of Shilajit (1.0000 $\pm 0.0005 \mathrm{~g})$ was dissolved in de-ionised water and diluted up to $100 \mathrm{ml}$. The amount of $\mathrm{Fe}, \mathrm{Zn}, \mathrm{Cr}, \mathrm{Mn}, \mathrm{Co}$ and $\mathrm{Pb}$ was found to be $1.968 \mathrm{mg}$ $\mathrm{g}^{-1}, 0.8705 \mathrm{mg} \mathrm{g}^{-1}, 0.1138 \mathrm{mg} \mathrm{g}^{-1}, 0.0260 \mathrm{mg} \mathrm{g}^{-1}, 0.0051 \mathrm{mg} \mathrm{g}^{-1}$ and $0.0008 \mathrm{mg}$ $\mathrm{g}^{-1}$ respectively in sample $\mathrm{A}$, On the other hand, the corresponding compounds in sample B recorded $0.321 \mathrm{mg} \mathrm{g}^{-1}, 0.0213 \mathrm{mg} \mathrm{g}^{-1}, 0.0154 \mathrm{mg} \mathrm{g}^{-1}, 0.0147 \mathrm{mg} \mathrm{g}^{-1}$, $0.0055 \mathrm{mg} \mathrm{g}^{-1}$ and $0.0023 \mathrm{mg} \mathrm{g}^{-1}$ respectively. These results are tabulated in Figure 1. Nickel and copper were not detected in both samples while physicchemical properties of shilajit samples have been shown in Table 1.

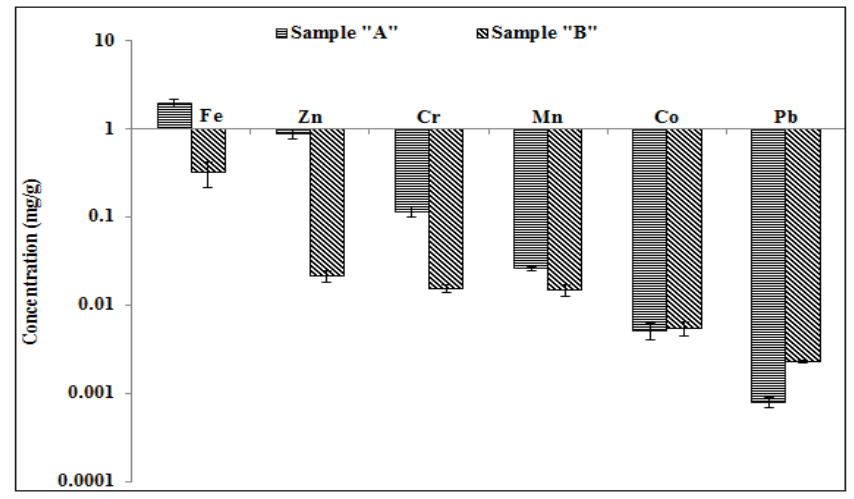

Figure 1: Concentration of heavy metals in Shilajit samples.

Table 1: Physical properties of Shilajit samples collected from Gilgit and Chellas.

\begin{tabular}{cll}
\hline S/No & Parameters & Results \\
\hline 1 & Colour & Colour of both samples is same, pale-brown to blackish \\
2 & Odour & Smells like stale cow urine, both A and B \\
3 & Physical state & Sample A is semi solid, while B is in solid state \\
4 & $\mathrm{pH}$ & Water solutions (2 g/50 mL) of both are neutral (using pH-Meter and \\
& & pH-paper) \\
5 & Moisture & Sample A contains $25 \%$ moisture while B contains $10 \%$ \\
6 & Flame test & Sample A and B are inflammable, burn with smoky flame \\
7 & Solubility & Both samples are soluble in water \\
\hline
\end{tabular}


The results show that the shilajit sample collected from Gilgit (sample A) contains higher percentage of $\mathrm{Fe}, \mathrm{Zn}, \mathrm{Mn}$, and Co than Shilajit from Chellas (sample B) which contains higher percentage of $\mathrm{Cr}$ and $\mathrm{Pb}$. The percentages of $\mathrm{Fe}, \mathrm{Zn}, \mathrm{Cr}, \mathrm{Mn}, \mathrm{Co}$ and $\mathrm{Pb}$ were found to be $0.1968 \%, 0.08705 \%, 0.01138 \%$, $0.0026 \%, 0.00051 \%$ and $0.00008 \%$ respectively, in sample A as shown in Figure 2 while, $0.0321 \%, 0.00213 \%, 0.00154 \%, 0.00147 \%, 0.00055 \%$ and $0.00023 \%$ respectively, in sample B as shown in Figure 3.

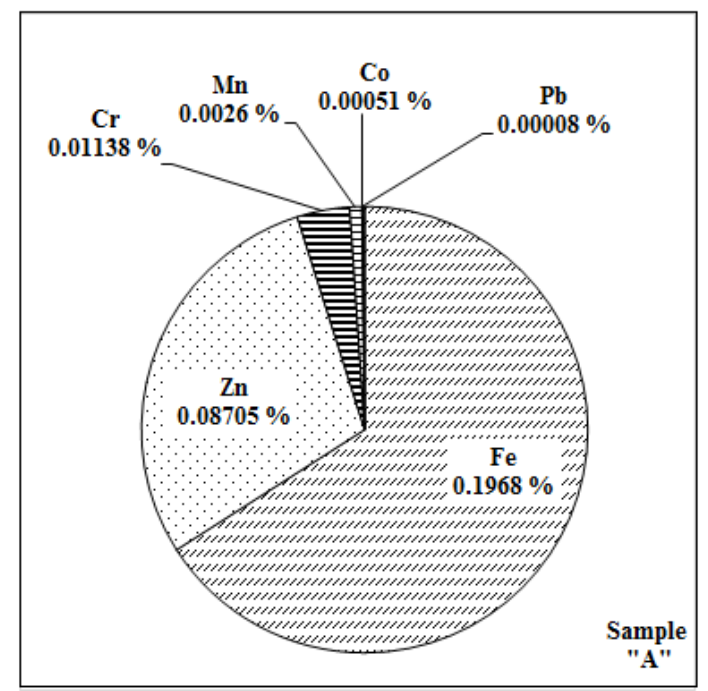

Figure 2: Percentage of heavy metals in Shilajit sample A.

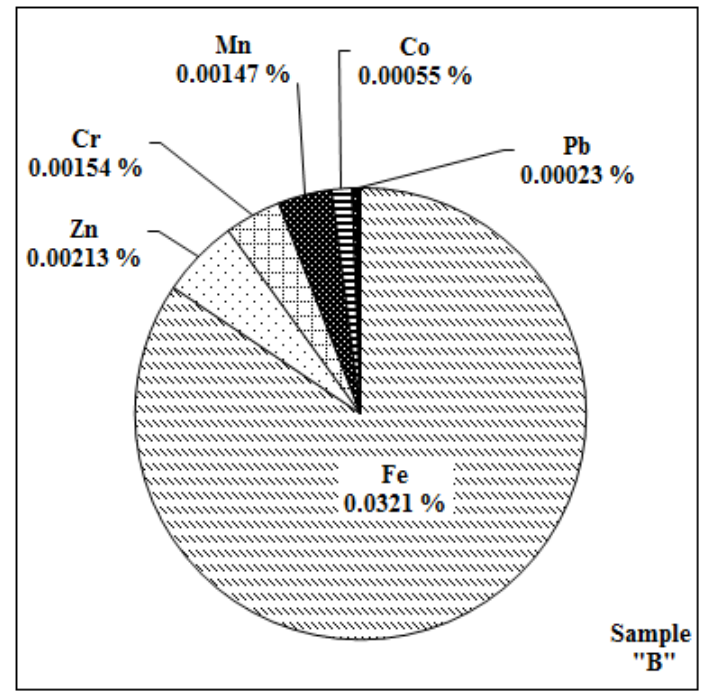

Figure 3: Percentage of heavy metals in Shilajit sample B. 
The data is in strong contradiction with studies of Ayurvedic HMPs sold outside the United States and herbal remedies from other indigenous healing traditions which reported risk factors associated with high metal concentrations. In England, $30 \%$ of Ayurvedic HMPs samples contained lead, mercury and/or arsenic. ${ }^{10}$ In 22 out of 28 Ayurvedic HMPs purchased in India, 64\% contained lead and mercury, and $41 \%$ contained arsenic. ${ }^{11}$ Traditional medicines from China, ${ }^{12}$ Malaysia, ${ }^{13}$ Mexico, ${ }^{14}$ Africa $^{15}$ and the Middle East ${ }^{16}$ have also been shown to contain heavy metals.

This study indicates that the Shilajit samples contain heavy metals in such a ratio, which is not harmful to human body and may be used as a safe herbal remedy in numerous diseases. Concentration of metals in Shilajit samples will provide baseline data and there is a need for intensive sampling of the same for quantification of the results. Soil, plant and water quality monitoring, is a prerequisite in order to stop potential health hazards attached with its use.

\section{ACKNOWLEDGEMENT}

The author Muhammad Rahim is grateful to Universiti Sains Malaysia and The World Academy of Sciences (TWAS) for providing TWAS-USM fellowship.

\section{REFERENCES}

1. Dutt, U. C. \& King, G. (1877). Materia medica of the Hindus. Calcutta: Machine Press.

2. Bhishagratna, K. K. \& Samhita, S. (1998). Varanasi, vol. 2. Delhi: Chowkhamba Sanskrit Series Office.

3. Halpern, M. (2003). Principles of Ayurvedic medicine, 5th ed. Grass Valley, CA: California College of Ayurveda.

4. Chopra, R. N. et al. (1958). Chopra's indigenous drugs of India, 2nd ed. Calcutta: B. K. Dhur of Academic Publishers.

5. Ghosal, S. et al. (1991). The need for formulation of Shilajit by its isolated active constituents. Phytother. Res., 5, 211-216, DOI: 10.1002/ ptr.2650050505.

6. Mukherjee, B. \& Patra, A. (1992). Traditional medicine. Presented at the Proceedings of International Seminar, 7-9 November, 308-319, Calcutta, India.

7. Murthy, K. R. S. (2001). Astanga hrdayam, 5th ed. Delhi: Krishnadas Academy.

8. Tierra, M. (1988). Planetary herbology. Twin Lakes, WI: Lotus Press. 
9. Ernst, E. (2002). Heavy metals in traditional Indian remedies. Eur. J. Clin. Pharmacol. 57, 891-896, DOI: 10.1007/s00228-001-0400-y.

10. McElvaine, M. D. et al. (1990). Lead poisoning from the use of Indian folk medicines. J. Amer. Med. Assoc., 264, 2212-2213.

11. Aslam, M., Davis, S. S. \& Healy, M. A. (1979). Heavy metals in some Asian medicines and cosmetics. Public Health, 93, 274-284, DOI: 10.1016/S0033-3506(79)80078-5.

12. Ko, R. J. (1998). Adulterants in Asian patent medicines. New Eng. J. Med., 339, 847.

13. Ang, H. H., Lee, E. L. \& Matsumoto, K. (2003). Analysis of lead content in herbal preparations in Malaysia. Hum. Exp. Toxicol., 22, 445-451.

14. Baer, R. D. et al. (1998). Mexican use of lead in the treatment of empacho: Community, clinic, and longitudinal patterns. Soc. Sci. Med., 47, 1263-1266, DOI: 10.1016/S0277-9536(98)00183-X.

15. Lekouch, N. et al. (2001). Lead and traditional Moroccan pharmacopoeia. Sci. Total Environ., 280, 39-43, DOI: 10.1016/S0048-9697(01)00801-4.

16. Al-Khyat, A., Menon, N. S. \& Alidina, M. R. (1997). Acute lead encephalopathy in early infancy: Clinical presentation and outcome. Ann. Trop. Paediatr., 17, 39-44. 